\title{
BMJ Open What are the prevalence and factors associated with sexual dysfunction in breastfeeding women? A Brazilian cross-sectional analytical study
}

\author{
Miguel Fuentealba-Torres, ${ }^{\oplus 1}$ Denisse Cartagena-Ramos, ${ }^{\odot 1}$ Inês Fronteira, ${ }^{2}$ \\ Lúcia Alves Lara, ${ }^{3}$ Luiz Henrique Arroyo, ${ }^{4}$ Marcos Augusto Moraes Arcoverde, ${ }^{1}$ \\ Mellina Yamamura, ${ }^{1}$ Lucila Castanheira Nascimento, ${ }^{1}$ Ricardo Alexandre Arcêncio ${ }^{1}$
}

To cite: Fuentealba-Torres M, Cartagena-Ramos D, Fronteira I, et al. What are the prevalence and factors associated with sexual dysfunction in breastfeeding women? A Brazilian cross-sectional analytical study. BMJ Open 2019;9:e025833. doi:10.1136/ bmjopen-2018-025833

- Prepublication history and additional material for this paper are available online. To view these files, please visit the journal online (http://dx.doi. org/10.1136/bmjopen-2018025833).

Received 9 August 2018 Revised 6 March 2019 Accepted 7 March 2019

Check for updates

(C) Author(s) (or their employer(s)) 2019. Re-use permitted under CC BY-NC. No commercial re-use. See rights and permissions. Published by BMJ.

For numbered affiliations see end of article.

Correspondence to Dr Miguel Fuentealba-Torres; mfuentealba@usp.br

\section{ABSTRACT}

Objective This study determined the prevalence and factors associated with sexual dysfunction in breastfeeding women.

Design Cross-sectional analytical study.

Setting Population-based study of individuals living in the northeast region of São Paulo state, Brazil.

Participants From May to August 2017, 372 women aged $\geq 18$ years were selected who gave exclusive, predominant or complementary breast feeding up to 23 months postpartum, and who did not have contraindications for the resumption of intercourse. Pregnant women, those diagnosed with mental health problems, users of medications that affect sexual function (antihypertensives, antidepressants or antipsychotics) and women unable to read or understand the instructions for the study were excluded.

Primary and secondary outcome measures The breastfeeding women completed the Female Sexual Function Index, the EUROHIS-QOL 8-item index and a questionnaire to collect participants' sociodemographic, clinical and interpersonal data. A bivariate analysis was performed, and variables with $p$ values $<0.20$ were analysed by multivariate logistic regression.

Results Sexual dysfunction was present in $58.3 \%$ of the study population. Factors significantly associated with female sexual dysfunction (FSD) included placing a low importance on sexual intercourse (adjusted OR $[A O R]=2.49,95 \% \mathrm{Cl}=1.22$ to 5.09 ), limited communication with the partner $(\mathrm{AOR}=2.64,95 \% \mathrm{Cl}=1.43$ to 4.86$)$, decreased frequency of sexual intercourse $(A O R=2.17$, $95 \% \mathrm{Cl}=1.30$ to 3.61$)$ and low quality of life $(A O R=2.23$, $95 \% \mathrm{Cl}=1.33$ to 3.74 ).

Conclusions The prevalence of FSD appears with a great magnitude in breastfeeding women. The risk factors for sexual dysfunction are biopsychosocial and these findings may lead to improved counselling for prenatal and postnatal care.

\section{INTRODUCTION}

Female sexual dysfunction (FSD) has been defined as distress caused by the unwanted presence or absence of sexual desire, sexual
Strengths and limitations of this study

- This study provides new information on the prevalence of sexual dysfunction in breastfeeding women in Brazil.

- The study showed associations to sexual dysfunction in breastfeeding women through multivariate analysis.

- The use of validated measurement instruments will allow the findings to be compared with other studies on the same population.

- The study was limited by the finite gynaecological and obstetric histories obtained for the participants.

- Because of the study's design, it was not possible to confirm the cause of sexual dysfunction, in a causeeffect perspective.

arousal, orgasm and/or associated sexual pain disorder. ${ }^{1}$ FSD affects approximately $40 \%-50 \%$ of women, irrespective of age. ${ }^{2}$ In Brazil, FSD also has a high prevalence regardless of age. ${ }^{3}$ A previous study of Brazilian women reported the prevalence of sexual problems in those over 18 years of age at $49.0 \%{ }^{4}$

Previous studies of general populations reported that sociodemographic factors, such as age, religious belief and low educational and socioeconomic levels, are associated with FSD. ${ }^{5}$ Clinical and interpersonal factors, such as relationship duration, androgen level and chronic disease, ${ }^{7-9}$ are also associated with sexual problems. Moreover, poor communication of couples, ${ }^{5}$ low interest in sex and the perception of low frequency of sexual activities, ${ }^{10}$ and erectile dysfunction are associated with FSD. ${ }^{11}$ A decreased quality of life (QoL) may also be associated with FSD, ${ }^{12}$ and QoL may decline in the first 6 months after delivery. ${ }^{13}$ 
In particular, FSD during breast feeding may be related to hyperprolactinaemia and physiological hypo-oestrogenism, ${ }^{14-17}$ which can lead to poor vaginal lubrication and dyspareunia. ${ }^{18} 19$ A decrease in sex hormones ${ }^{14}$ can negatively affect the sexual satisfaction of women. ${ }^{20}$ In addition, some women experience perineal trauma during childbirth, and this can impair their ability to achieve orgasm, leading to sexual dissatisfaction. ${ }^{17}$ Moreover, the responsibilities of motherhood and the demands of childcare may have a negative psychological impact on the sexual response of breastfeeding women. ${ }^{21}$

Previous research has studied the relationship of FSD with perineal trauma, ${ }^{17} 19$ with dyspareunia among primiparous women, ${ }^{18}$ with type of delivery ${ }^{22}$ and with sexual dysfunction in the postpartum period. ${ }^{21}{ }^{23-25}$ However, prevalence and factors associations with sexual dysfunction have not been studied specifically in breastfeeding women and hence, the situation is unknown in Brazil. ${ }^{3}$

Protection, promotion and support of breastfeeding women are global goals of the 2030 Agenda for Sustainable Development. ${ }^{26}$ Breast feeding impacts both child and maternal health, reducing the rates of non-communicable diseases, such as diabetes, obesity and breast cancer, and having a positive effect on the reduction of poverty and on economic growth. ${ }^{27}$

The determinants of breast feeding are multifactorial, ${ }^{28}$ and knowledge of the prevalence and factors associated with sexual dysfunction of breastfeeding Brazilian women is extremely important. This is because in Brazil there are no epidemiological studies available on this issue, and the magnitude of FSD is unknown. In this context, this study was designed to determine the prevalence and factors associated with sexual dysfunction in breastfeeding women.

\section{METHODS}

\section{Study design and participants}

This cross-sectional analytical study was conducted in the northeast region of the state of São Paulo, Brazil, from May to August 2017. Participants were heterosexual women $\geq 18$ years of age, who practised exclusive, predominant or complementary breast feeding for up to 23 months after delivery. In addition, they had no medical contraindications to resuming vaginal intercourse, such as surgical complications after delivery, puerperal infection, haemorrhage or uterine inversion. Those excluded were pregnant women, women diagnosed with mental health problems, women using medications that affect sexual function (antihypertensives, antidepressants or antipsychotics) and women unable to read or understand the questionnaires.

The calculation of the sample size was based on the data from the database of the Nutrition Surveillance System (SISVAN) of the Ministry of Health of Brazil. ${ }^{29}$ This system performed epidemiological surveillance of women who breast feed up to 23 months after delivery, with coverage of $99 \%$ of municipalities in all regions of
Brazil. The SISVAN data were collected by doctors and nurses in health centres and entered into the SISVAN database by administrative personnel.

SISVAN generated annual statistics on three types of breast feeding: 'exclusive breastfeeding', in which the woman fed her child only with breast milk, with no other liquid or solid food except for the administration of vitamins, minerals and/or medicines; 'predominant breastfeeding', in which the woman fed her child with breast milk and with water or water-based drinks and 'complementary breastfeeding', in which the woman fed her child with breast milk along with solid and semisolid foods, including non-human milk. ${ }^{29}$

The minimal sample size was 372 participants, considering a total population of 4839 breastfeeding women living in the northeast region of the state of São Paulo. A probabilistic calculation was made for a known population and an unknown FSD prevalence, considering CIs at $95 \%$, an accuracy of $5 \%$ and a statistical power of $80 \%$, with a participation loss of $5 \% .^{30}$

To gather data, the medical histories of women who were scheduled for medical appointments at health facilities were examined. The medical records of the women who matched the inclusion criteria were selected and successively numbered. Initially, the sample for the study was drawn at random from this data set. Subsequently, selected women were invited to participate voluntarily in the study.

Data were collected from May to August 2017 by professionals trained in family health, who had clinical experience in sexual, prenatal and postnatal healthcare. The interviews were conducted in private rooms located in the health facilities. The average time for each interview was $20 \mathrm{~min}$.

\section{Study variables and measurement}

The dependent variable was the presence of FSD, determined from the established cut-off point (see below) on the Female Sexual Function Index (FSFI). The FSFI was a self-administered instrument used to assess female sexual function, ${ }^{31}$ was considered a gold standard test, and had been validated in Brazil. ${ }^{32}$ The FSFI assessed female sexual function in the previous 4 weeks using 19 multiple-choice questions in six domains: desire, arousal, lubrication, orgasm, satisfaction and pain. The scores for each question ranged from 0 to 5 points, and the values of each domain were added and then multiplied by a correction factor to obtain the total score, which ranges from 2 to 36 points. A total score below 26.55 points suggested FSD. Cut-off points were also used for each FSD domain (4.28 for desire, 5.08 for arousal, 5.45 for lubrication, 5.05 for orgasm, 5.04 for satisfaction and 5.51 for pain), and scores less than or equal to these values indicated sexual problems in that domain. ${ }^{33}$

The effect of sociodemographic, clinical, interpersonal relations and QoL variables on FSD were examined (table 1). Through a clinical interview, a structured questionnaire was used to collect sociodemographic data 
Table 1 Descriptive characteristics of the respondents $(n=355)$

\begin{tabular}{|c|c|c|c|c|}
\hline Numeric variables & Min* & Maxt & Mean \pm SD & Median \\
\hline Age, years & 18 & 45 & $26.5 \pm 6.68$ & 25.00 \\
\hline Family income, US\$‡ & 111.20 & 1680.67 & $514.28 \pm 287.42$ & 448.18 \\
\hline Relationship duration, years & 1 & 28 & $6.27 \pm 4.50$ & 5.00 \\
\hline Time from birth to resumption of intercourse, days & 3 & 120 & $44.96 \pm 16.62$ & 42.00 \\
\hline EUROHIS-QOL 8-item index, total score & 14 & 40 & $29.44 \pm 4.89$ & 30.00 \\
\hline
\end{tabular}

Categorical variables $\quad$ n (\%)

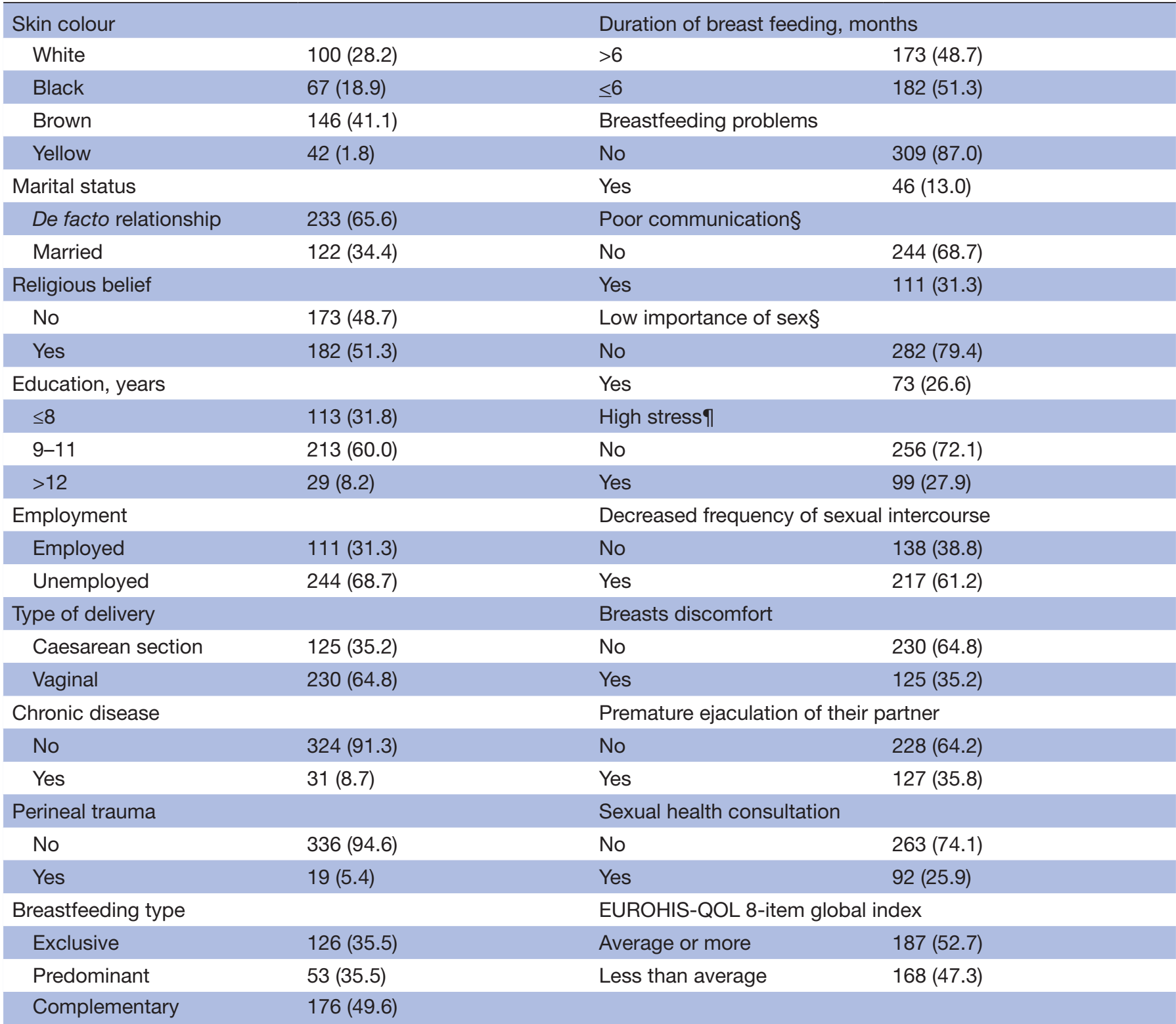

${ }^{*}$ Minimum

†Maximum

łUS\$1=R\$3.42 [11 May 2018]

§Low or very low on Likert-type scale.

१High or very high on Likert-type scale.

(age, skin colour, marital status, religious beliefs, family income, years of study and employment), clinical data (type of birth, chronic disease, perineal trauma, breastfeeding time, type of breast feeding and breastfeeding problems) and interpersonal data (time in relationship, resumption of sex, premature ejaculation of their partner, breast discomfort and sexual health consultation). The levels of communication with their partner, 
the importance of sex and stress were evaluated using a Likert-type scale: 1 , very low; 2 , low; 3 , moderate; 4 , high and 5 , very high. ${ }^{34}$

QoL was assessed using the EUROHIS-QOL 8-item index, which was validated in Brazil.

${ }^{35}$ This single-dimension instrument evaluated self-perceived QoL during the previous 2 weeks, by assessment of physical, psychological and social relations, and environment domains. This instrument had eight items, each scored from 1 to 5 points, for a total score range of 8-40, with a higher score indicating a better QoL.

\section{Data analysis}

The database was constructed using independent double data entry, and all descriptive and inferential analyses were performed using SPSS V.16.0. Absolute and relative frequencies and percentages were calculated for the categorical variables, and median, mean and SD for the numeric variables. The dependent variable FSD was classified by the cut-off point in the FSFI instrument; sexual dysfunction for each domain of the FSFI was determined using their respective cut-off points.

Women were classified as having low or high QoL based on a total score above or below the average QoL in the sample. Age, family income, relationship duration and time until resumption of intercourse were converted from continuous to categorical dichotomous variables, taking the value of the median as a reference. The variables, level of communication by the couple, importance of sex and level of stress, that presented $\leq 2$ points, on the Likert scale, were dichotomised in the categories: poor communication, low importance of sex and high stress. The explanatory variables were binary, and a $\chi^{2}$ test was applied. In addition, crude ORs and 95\% CIs were calculated. Variables whose $p$ values were $<0.2$ were then entered into a binary logistic regression model. The criteria for maintenance of a variable in the final model considered its level of significance and the quality of fit of the model (using the value of the likelihood function and the Hosmer-Lemeshow test). The predictive capacity of the model was also examined by plotting a receiver operating characteristic (ROC) curve. For all statistical tests, the type I error rate was set at 0.05 .

\section{Patient and public involvement}

Participants were not involved in the design and conception of the study. The results of this study will be disseminated to the community and health personnel of the northeast region of the state of São Paulo.

\section{Ethical considerations}

The study was performed according to the Declaration of Helsinki.

All participants were informed of the aim of the study, the risks and the benefits.
Table 2 Prevalence of overall female sexual dysfunction and in the individual domains $(n=355)$

\begin{tabular}{ll}
\hline FSD prevalence* & $\mathbf{n}(\%)$ \\
\hline Overall FSD & $207(58.3)$ \\
\hline Domains & \\
$\quad$ Sexual desire & $295(83.0)$ \\
\hline Sexual arousal & $295(83.3)$ \\
\hline Lubrication & $315(88.7)$ \\
\hline Orgasm & $271(76.3)$ \\
\hline Sexual satisfaction & $181(50.9)$ \\
\hline Sexual pain & $294(82.8)$ \\
\hline
\end{tabular}

*Estimated from cut-off points in the FSFI.

FSD, female sexual dysfunction; FSFI, Female Sexual Function Index.

\section{RESULTS}

We initially recruited 372 breastfeeding women, but 17 were excluded, $5(0.01 \%)$ refused to participate and 12 $(0.03 \%)$ had difficulty completing the questionnaires. The final sample of 355 women $(95.4 \%)$ had a mean age of $26.5 \pm 6.68$ years (range: $18-45$ ), $41.1 \%$ were brown skinned, $34.3 \%$ were married, $8.2 \%$ had more than 12 years of education, $51.3 \%$ had religious beliefs, $31.3 \%$ had formal work, and family income was US $\$ 514.28 \pm 287.42$ (range: 111.20-1600.00; table 1).

The average FSFI score for the sample was 24.72 points ( $\mathrm{SD}=4.75$; range: $10.20-35.1$ ). On the basis of the FSFI cut-off point, 207 women $(58.3 \%)$ had sexual dysfunction $($ FSFI $<26.55)$. The individual domain with the highest prevalence of dysfunction was vaginal lubrication $(n=315$, $88.7 \%$ ), and the one with the lowest was sexual satisfaction $(\mathrm{n}=181,50.9 \%$; table 2$)$.

The overall QoL index, calculated from the sum of all eight items, had a mean \pm SD of $29 \pm 4.89$ points (range: 14-40; table 3).

Table 4 shows the results of bivariate analyses of the variables that presented with $p$ values $<0.2$. Variables that had $p$ values $<0.2$, and were included in the multivariate logistic regression model, were: black skin colour, yellow skin colour, de facto relationship, in the home or unemployed, high stress, low importance of sexual relations, little communication with partner, decrease in the frequency of sexual intercourse compared with the period before breast feeding, breasts discomfort, premature ejaculation of their partner, receipt of consultation for sexual health and low QoL. Variables that had $p$ values $>0.2$, and therefore were not included in the multivariate logistic regression model, were: age, white skin colour, brown skin colour, religious beliefs, education years, type of birth, chronic disease, perineal trauma, breastfeeding type, duration of breast feeding and breastfeeding problems.

Table 5 shows the results of the multivariate logistic regression model.

These results indicate FSD was positively associated with low importance of sex in the relationship (adjusted OR 
Table 3 Results of the EUROHIS-QOL 8-item index ( $n=355)$

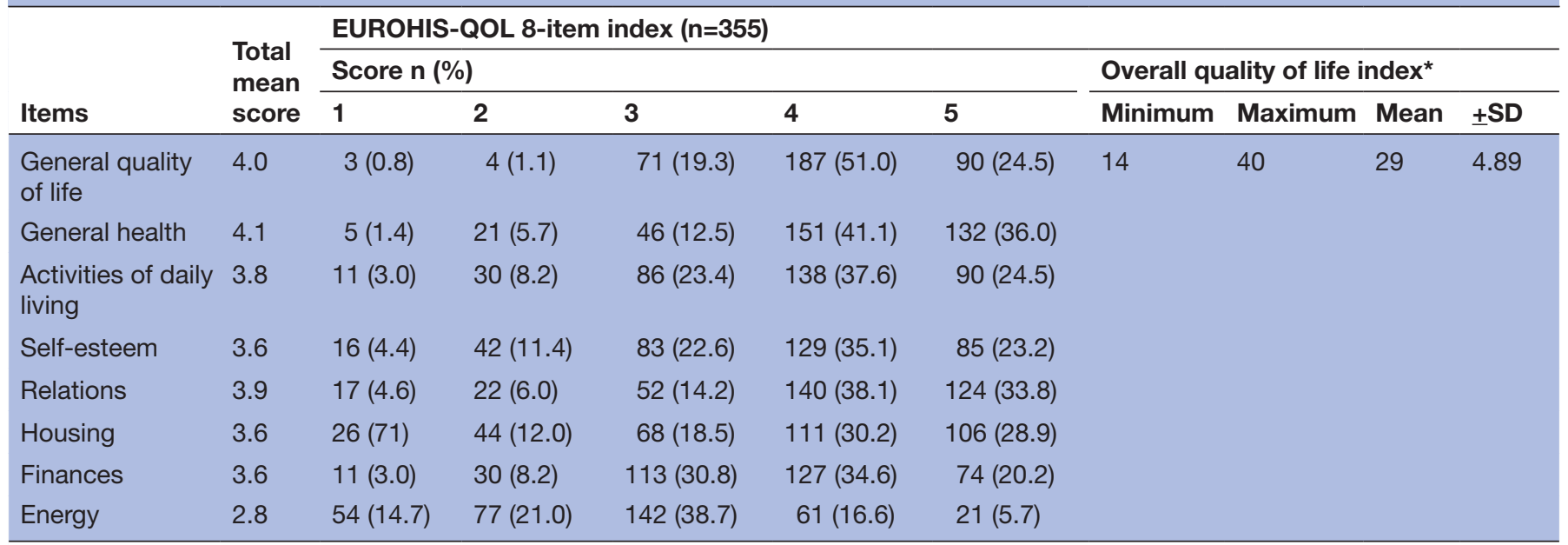

*Index calculated from the sum of all eight items.

$[\mathrm{AOR}]=2.49,95 \% \mathrm{CI}=1.22$ to 5.09 ), limited communication with the partner $(\mathrm{AOR}=2.64,95 \% \mathrm{CI}=1.43$ to 4.86$)$, a decrease in frequency of sexual intercourse compared with the period before breast feeding $(\mathrm{AOR}=2.17$, $95 \% \mathrm{CI}=1.30$ to 3.61$)$ and low QoL $(\mathrm{AOR}=2.23$, $95 \% \mathrm{CI}=1.33$ to 3.74$)$. In addition, FSD was negatively associated with sexual health consultation $(\mathrm{AOR}=0.33$, $95 \% \mathrm{CI}=0.19$ to 0.58 ). This multivariate model had goodness of fit, as indicated by the Hosmer-Lemeshow test $\left(\chi^{2}=6.00, p\right.$ value $\left.=0.65\right)$ and the Nagelkerke test $(30.2 \%)$.

We also calculated the ROC curve to describe the predictive capacity of the logistic regression model. The results indicated a satisfactory prediction of FSD, with an area under the curve of $0.79 \pm 0.02(95 \% \mathrm{CI}=0.74$ to 0.84 ; $\mathrm{p}$ value $<0.01$. (figure 1 ).

\section{DISCUSSION}

The present study determined the prevalence and factors associated with sexual dysfunction in women who breast fed up to 23 months after delivery. All women agreed to participate freely in this study. The final sample size $(n=355)$ provided a statistical power of $80 \%$.

Although the knowledge of FSD in breastfeeding women is limited, ${ }^{36}$ and the prevalence of FSD in breastfeeding women is still unknown, previous studies have shown that it is a common problem in women postpartum, with a prevalence of $64.3 \% .{ }^{37}$ Our current study showed that the prevalence of FSD in women who breast fed was $18.3 \%$ higher than the prevalence reported for the general population of women older than 18 years. ${ }^{5}{ }^{20}$ Notably, $58.3 \%$ of our subjects had FSD, and about two-thirds of the women had individual FSFI scores below the cut-off points in each of the domains. The lubrication domain was the most affected domain in our participants. Sexual desire and sexual arousal domains were the next two most affected domains among our subjects. Most of the factors predictive of FSD were interpersonal variables.
A total of $88.7 \%$ of our study subjects had low scores for the vaginal lubrication domain. This could be due to the high levels of prolactin during breast feeding, which leads to reduced oestrogen levels, high vaginal $\mathrm{pH}$, increased parabasal and intermediate cells, and decreased superficial cells. ${ }^{38}$ These atrophic changes in the vaginal mucosa may reduce vaginal lubrication, and therefore cause dyspareunia. $^{39}$ In our study population, $82.8 \%$ of the women reported sexual pain in parallel with poor lubrication, a relationship also reported in a previous study of middle-aged Chinese women. ${ }^{40}$

There is a known association of poor lubrication and sexual pain during or after intercourse with hypoactive sexual desire disorder (HSDD) in middle-aged women. ${ }^{41}$ HSDD is also related to high prolactin and decreased sex hormones, levels common in lactating women. The social context for these women, who need to take on new tasks as mothers, may also have psychological effects that decrease sexual desire and sexual arousal and reduce interpersonal interactions in a relationship. ${ }^{1622}$

Interestingly, women who attributed low importance to sex were 2.5 times more likely to have sexual dysfunction. Previous research indicated that low sexual interest can predict HSDD,$^{42}$ and more interest in sex protected against sexual dysfunction. ${ }^{7}$ New mothers often experience fatigue because of the demands of childcare and the task of breast feeding, which become priorities, especially in the first 6 months after childbirth. ${ }^{43}{ }^{44}$ In addition, breastfeeding women may give lower importance to sex due to a decreased interest in sex caused by physical changes after childbirth, such as weight gain, the presence of stretch marks or scars and changes in the perineal region. ${ }^{43-45}$

Women who had limited communication with their partners had a 2.2-fold increased risk of sexual dysfunction. Adequate communication in a relationship contributes to interpersonal well-being for the couple and improves the female sexual response. ${ }^{46}$ This finding is 
Table 4 Bivariate analysis of factors associated with FSD $(n=355)$

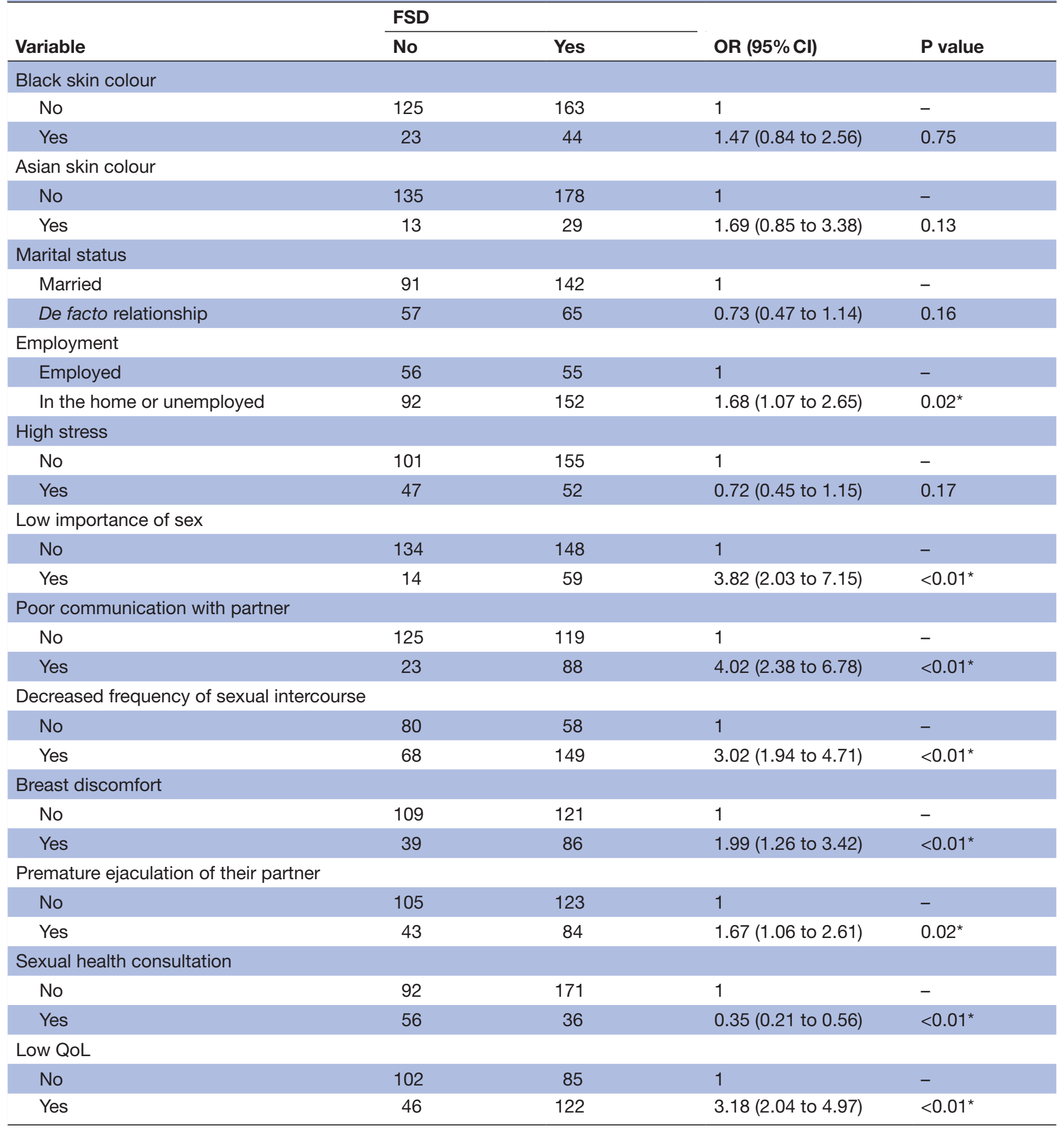

${ }^{*} P$ value $<0.05$

FSD, female sexual dysfunction; OR, gross OR; QoL, quality of life.

important because it suggests that incorporation of the sexual partner in clinical interventions may help to treat or prevent FSD.

Women generally report a decrease in frequency of sexual intercourse after childbirth, ${ }^{47}$ an association that deserves attention because it could increase the risk for FSD. $^{48}$ Our multivariate analysis also confirmed that breastfeeding women had a reduced frequency of sexual intercourse. A low QoL led to a 2.3-fold increased risk for sexual dysfunction in our sample. Breastfeeding women may have a low QoL due to the physical and emotional stress experienced during the first months of breast feeding. ${ }^{49}$ However, this interpretation is controversial, because there is evidence that sexual function 
Table 5 Multivariate analysis of factors associated with FSD $(n=355)$

\begin{tabular}{|c|c|c|c|c|}
\hline Variable & Parameters & SE & AOR $(95 \% \mathrm{Cl})$ & $P$ value \\
\hline Black skin colour & 0.12 & 0.33 & $1.13(0.60$ to 2.14$)$ & 0.71 \\
\hline Yellow skin colour & 0.57 & 0.39 & 1.77 (0.83 to 3.79$)$ & 0.14 \\
\hline In the home or unemployed & 0.46 & 0.28 & $1.58(0.92$ to 2.71$)$ & 0.10 \\
\hline High stress & 0.27 & 0.28 & 1.31 (0.75 to 2.29$)$ & 0.34 \\
\hline Poor communication with partner & 0.97 & 0.31 & 2.64 (1.43 to 4.86$)$ & $<0.01^{*}$ \\
\hline $\begin{array}{l}\text { Decreased frequency of sexual } \\
\text { intercourse }\end{array}$ & 0.77 & 0.26 & 2.17 (1.30 to 3.61$)$ & $<0.01^{*}$ \\
\hline Breast discomfort & 0.46 & 0.27 & 1.58 (0.93 to 2.68$)$ & 0.09 \\
\hline Premature ejaculation of their partner & 0.33 & 0.27 & 1.39 (0.82 to 2.37$)$ & 0.22 \\
\hline
\end{tabular}

Hosmer-Lemeshow test $\chi^{2}=6.00$, p value $=0.65$; Nagelkerke test $=30.2 \%$. ${ }^{*} P$ value $<0.05$.

AOR, adjusted OR; FSD, female sexual dysfunction; QoL, quality of life.

after birth is influenced by a woman's perception of her partner's postpartum sexual response. As such, factors, such as breast feeding, vaginal issues, stress, body image and social support, may be less important than her partner's behaviour in understanding female sexual responses after birth. ${ }^{49}$ Thus, further research is needed to clarify the role of QoL in predicting sexual dysfunction in breastfeeding women.

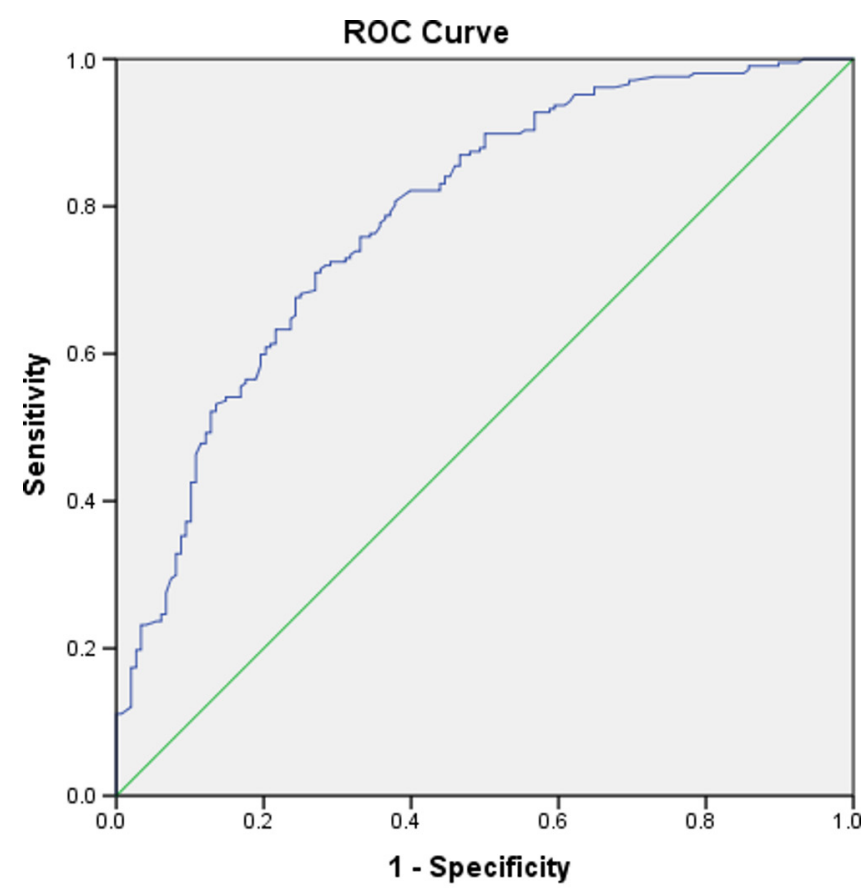

Diagonal segments are produced by ties.

Figure 1 Receiver operating characteristics (ROCs) used to test the predictive of the bivariate logistic regression model.
A sexual health consultation provides an opportunity for counselling and professional support that could help to prevent sexual problems. ${ }^{225152}$ The health team could identify risk factors and plan appropriate interventions during regular appointments, offering an improved holistic approach in familiar surroundings. ${ }^{39} 52$ Evidence indicates that women who receive sexual health consultations report better sexual performance. ${ }^{53}{ }^{54}$ Despite this, very few breastfeeding women seek counselling for sexual problems. A previous study showed that only $28 \%$ of postpartum women discussed changes in their sex lives with the health team. ${ }^{39}$ Similarly, only $34 \%$ of health professionals reported being interested in discussing the resumption of sexual activities after the sixth week postpartum. $^{55}$

The high prevalence of FSD among women who breast feed demonstrates the importance of health professionals actively assessing sexual function among these patients. All women who breast feed should have the opportunity to fulfil their full sexual health potential and should not be at a disadvantage in achieving this goal, because of the care of their child. This means that healthcare personnel must create opportunities to improve the health of women who breast feed, so as to provide for comprehensive sexual healthcare.

More qualified and educated professionals will be able to help improve the sexual life of women who breast feed, through guidance on topics, such as the use of lubricants to prevent dyspareunia, and breast feeding before vaginal intercourse to prevent the escape of breast milk during orgasm. In addition, counselling of the woman and her sexual partner can facilitate the readjustment of their patterns of sexual relations during the period of breast feeding. 
Finally, because the determinants of breast feeding are multifactorial, ${ }^{28}$ FSD could interfere in the predisposition to breast feed, because FSD decreases the level of well-being. ${ }^{22}$ Therefore, prevention of problems of sexual dysfunction among women who breast feed could contribute not only to the maintenance of sexual health of women, but also act to promote breast feeding; however, this hypothesis needs to be tested with other studies.

\section{CONCLUSIONS}

The high prevalence of FSD among breastfeeding women is a stimulus to the planning of preventive measures, especially in primary healthcare. Our study showed that the risk factors for FSD involve interpersonal aspects, and suggested educational programmes for implementation in prenatal and postnatal care.

Precise estimates of FSD prevalence are important in understanding the international magnitude of this problem in providing care to postnatal women, and in identifying the risk in breastfeeding women. Our findings encourage further epidemiological studies that will make it possible to compare the results in this report with those of other communities.

\section{Author affiliations}

${ }^{1}$ Maternal-Infant and Public Health, University of Sao Paulo, Ribeirão Preto, São

Paulo, Brazil

${ }^{2}$ Department of International Public Health and Biostatistics, Universidade Nova de Lisboa Escola Nacional de Saude Publica, Lisboa, Lisboa, Portugal

${ }^{3}$ Departament of Gynecology and Obstetrics, University of Sao Paulo, Ribeirão Preto, São Paulo, Brazil

${ }^{4}$ Maternal-Infant and Public Health, University of Sao Paulo, Sao Paulo, São Paulo, Brazil

Acknowledgements The authors thank the breastfeeding women for their willingness to participate in this study.

Contributors MF-T, DC-R, LHA, MAMA and MY interviewed the women and, collected and tabulated the data. IF, LAL, LCN and RAA also contributed to the study design and supervision of the study. MF-T, DC-R, IF, LAL, LHA, MAMA, MY, LCN and RAA contributed to the analysis and interpretation of data, and drafting. All authors contributed to the critical review of the manuscript and the final approval of the version.

Funding The study is funded by the Coordination for the Improvement of Higher Education Personnel (CAPES) and National Council for Scientific and Technological Development (CNPq), PEC-PG 9191134/2015 and PEC-PG 9243143/2015.

\section{Competing interests None.}

Patient consent for publication Not required.

Ethics approval The study was approved by the Research Ethics Committee of the University of São Paulo, under authorisation number CAAE 67039517.5.0000.5393.

Provenance and peer review Not commissioned; externally peer reviewed.

Data sharing statement The data sets used and/or analysed during the current study are available from the corresponding author on reasonable request.

Open access This is an open access article distributed in accordance with the Creative Commons Attribution Non Commercial (CC BY-NC 4.0) license, which permits others to distribute, remix, adapt, build upon this work non-commercially, and license their derivative works on different terms, provided the original work is properly cited, appropriate credit is given, any changes made indicated, and the use is non-commercial. See: http://creativecommons.org/licenses/by-nc/4.0/.

\section{REFERENCES}

1. Basson R. The female sexual response: a different model. J Sex Marital Ther 2000;26:51-65.

2. McCabe MP, Sharlip ID, Lewis R, et al. Incidence and prevalence of sexual dysfunction in women and men: A consensus statement from the fourth international consultation on sexual medicine 2015. J Sex Med 2016;13:144-52.

3. Wolpe RE, Zomkowski K, Silva FP, et al. Prevalence of female sexual dysfunction in Brazil: A systematic review. Eur J Obstet Gynecol Reprod Biol 2017;211:26-32.

4. Abdo CH, Oliveira WM, Moreira ED, et al. Prevalence of sexual dysfunctions and correlated conditions in a sample of Brazilian women-results of the Brazilian study on sexual behavior (BSSB). Int J Impot Res 2004;16:160-6.

5. Ibrahim ZM, Ahmed MR, Sayed Ahmed WA. Prevalence and risk factors for female sexual dysfunction among Egyptian women. Arch Gynecol Obstet 2013;287:1173-80.

6. Rahman S. Female Sexual Dysfunction Among Muslim Women: Increasing Awareness to Improve Overall Evaluation and Treatment. Sex Med Rev 2018;6.

7. Hayes RD, Dennerstein L, Bennett CM, et al. Risk factors for female sexual dysfunction in the general population: exploring factors associated with low sexual function and sexual distress. J Sex Med 2008:5:1681-93.

8. Lo SS, Kok WM. Sexual behavior and symptoms among reproductive age Chinese women in Hong Kong. J Sex Med 2014;11:1749-56.

9. Wåhlin-Jacobsen S, Kristensen E, Pedersen AT, et al. Androgens and Psychosocial Factors Related to Sexual Dysfunctions in Premenopausal Women": "2016 ISSM Female Sexual Dysfunction Prize. J Sex Med 2017;14:366-79.

10. Song SH, Jeon H, Kim SW, et al. The prevalence and risk factors of female sexual dysfunction in young korean women: an internetbased survey. J Sex Med 2008;5:1694-701.

11. Grewal GS, Gill JS, Sidi H, et al. Prevalence and risk factors of female sexual dysfunction among healthcare personnel in Malaysia. Compr Psychiatry 2014;55 Suppl 1(Suppl 1):S17-22.

12. Nappi RE, Cucinella L, Martella S, et al. Female sexual dysfunction (FSD): Prevalence and impact on quality of life (QoL). Maturitas 2016;94:87-91.

13. Johnson CE. Sexual health during pregnancy and the postpartum. $J$ Sex Med 2011;8:1285-6.

14. Alder EM, Cook A, Davidson D, et al. Hormones, mood and sexuality in lactating women. Br J Psychiatry 1986;148:74-9.

15. van Anders SM, Hipp LE, Kane Low L. Exploring co-parent experiences of sexuality in the first 3 months after birth. J Sex Med 2013;10:1988-99.

16. Leeman $L M$, Rogers RG. Sex after childbirth: postpartum sexual function. Obstet Gynecol 2012;119:647-55.

17. Signorello LB, Harlow BL, Chekos AK, et al. Postpartum sexual functioning and its relationship to perineal trauma: a retrospective cohort study of primiparous women. Am J Obstet Gynecol 2001;184:881-90.

18. Alligood-Percoco NR, Kjerulff KH, Repke JT. Risk Factors for Dyspareunia After First Childbirth. Obstet Gynecol 2016;128:512-8.

19. McDonald E, Woolhouse H, Brown SJ. Consultation about Sexual Health Issues in the Year after Childbirth: A Cohort Study. Birth 2015;42:354-61.

20. Jaafarpour M, Khani A, Khajavikhan J, et al. Female sexual dysfunction: prevalence and risk factors. J Clin Diagn Res 2013;7:2877-80.

21. Woolhouse H, McDonald E, Brown S. Women's experiences of sex and intimacy after childbirth: making the adjustment to motherhood. J Psychosom Obstet Gynaecol 2012;33:185-90.

22. Convery KM, Spatz DL. Sexuality \& breastfeeding: what do you know? MCN Am J Matern Child Nurs 2009;34:218-23.

23. Acele EÖ, Karaçam Z. Sexual problems in women during the first postpartum year and related conditions. J Clin Nurs 2012;21:929-37.

24. Anbaran ZK, Baghdari N, Pourshirazi M, et al. Postpartum sexual function in women and infant feeding methods. J Pak Med Assoc 2015;65:248-52.

25. Millheiser $L$. Female sexual function during pregnancy and postpartum. J Sex Med 2012;9:635-6.

26. United Nations. Transforming our world: the 2030 agenda for Sustainable Development. 2015. Agenda for Sustainable Development web.pdf https://sustainabledevelopment.un.org/ content/documents/21252030 (accessed 13 Jan 2019).

27. Victora CG, Bahl R, Barros AJ, et al. Breastfeeding in the 21st century: epidemiology, mechanisms, and lifelong effect. Lancet 2016;387:475-90. 
28. Rollins NC, Bhandari N, Hajeebhoy N, et al. Why invest, and what it will take to improve breastfeeding practices? Lancet 2016;387:491-504

29. Brazil. Brazil. Food and Nutrition Surveillance Sistem. Minist. Heal. 2018 http://dabsistemas.saude.gov.br/sistemas/sisvanV2/.

30. Rothman KJ, Greenland S, Lash TL. Modern Epidemiology. 3rd Edition: Philadelphia Wolters Kluwer Health, 2015.

31. Rosen R, Brown C, Heiman J, et al. The Female Sexual Function Index (FSFI): a multidimensional self-report instrument for the assessment of female sexual function. J Sex Marital Ther 2000;26:191-208.

32. Thiel RdoRC, Dambros M, Palma PCR, et al. Tradução para português, adaptação cultural e validação do Female Sexual Function Index. Revista Brasileira de Ginecologia e Obstetrícia 2008;30:504-10.

33. Wiegel M, Meston C, Rosen R. The female sexual function index (FSFI): cross-validation and development of clinical cutoff scores. $J$ Sex Marital Ther 2005;31:1-20.

34. Likert R. A technique for the measurement of attitudes. Arch Psychol 1932;22:1-55

35. Pires AC, Fleck MP, Power M, et al. Psychometric properties of the EUROHIS-QOL 8-item index (WHOQOL-8) in a Brazilian sample. Braz J Psychiatry 2018;40:249-55.

36. Fuentealba-Torres M, Cartagena-Ramos D, Sierra JC, et al. What are the factors that contribute to the development of sexual dysfunction in breastfeeding women? A systematic scoping review protocol. BMJ Open 2018;8:e022863.

37. Khajehei M, Doherty M, Tilley PJ, et al. Prevalence and risk factors of sexual dysfunction in postpartum Australian women. J Sex Med 2015;12:1415-26.

38. Wisniewski PM, Wilkinson EJ. Postpartum vaginal atrophy. Am J Obstet Gynecol 1991;165:1249-54.

39. Barrett G, Pendry E, Peacock J, et al. Women's sexual health after childbirth. BJOG An Int J Obstet Gynaecol 2000;107:186-95.

40. Zhang C, Cui L, Zhang L, et al. Sexual activity and function assessment in middle-aged Chinese women using the female sexual function index. Menopause 2017;24:669-76.

41. Worsley R, Bell RJ, Gartoulla P, et al. Prevalence and predictors of low sexual desire, sexually related personal distress, and hypoactive sexual desire dysfunction in a community-based sample of midlife women. J Sex Med 2017;14:675-86.
42. O’Loughlin JI, Basson R, Brotto LA. Women With Hypoactive Sexual Desire Disorder versus Sexual Interest/Arousal Disorder: An Empirical Test of Raising the Bar. J Sex Res 2017:1-13.

43. Adanikin Al, Awoleke JO, Adeyiolu A, et al. Resumption of intercourse after childbirth in southwest Nigeria. Eur J Contracept Reprod Health Care 2015;20:241-8.

44. Barbara G, Pifarotti P, Facchin F, et al. Impact of Mode of Delivery on Female Postpartum Sexual Functioning: Spontaneous Vaginal Delivery and Operative Vaginal Delivery vs. Cesarean Section. J Sex Med 2016;13:393-401.

45. Song JE, Chae HJ, Kim CH. Changes in perceived health status, physical symptoms, and sleep satisfaction of postpartum women over time. Nurs Health Sci 2014;16:335-42.

46. Lianjun P, Aixia Z, Zhong W, et al. Risk factors for low sexual function among urban Chinese women: a hospital-based investigation. J Sex Med 2011;8:2299-304.

47. Rowland M, Foxcroft L, Hopman WM, et al. Breastfeeding and sexuality immediately post partum. Can Fam Physician 2005;51:1367.

48. Witherow MP, Chandraiah S, Seals SR, et al. Relational Intimacy Mediates Sexual Outcomes Associated With Impaired Sexual Function: Examination in a Clinical Sample. J Sex Med 2017;14:843-51.

49. Hipp LE, Kane Low L, van Anders SM. Exploring women's postpartum sexuality: social, psychological, relational, and birthrelated contextual factors. J Sex Med 2012;9:2330-41.

50. Hisasue S, Kumamoto Y, Sato Y, et al. Prevalence of female sexual dysfunction symptoms and its relationship to quality of life: a Japanese female cohort study. Urology 2005;65:143-8.

51. Avery MD, Duckett L, Frantzich CR. The experience of sexuality during breastfeeding among primiparous women. J Midwifery Womens Health 2000;45:227-37.

52. Yee LM, Kaimal AJ, Nakagawa S, et al. Predictors of postpartum sexual activity and function in a diverse population of women. $J$ Midwifery Womens Health 2013;58:654-61.

53. Robson KM, Brant HA, Kumar R. Maternal sexuality during first pregnancy and after childbirth. Br J Obstet Gynaecol 1981;88:882-9.

54. von Sydow K. Sexuality during pregnancy and after childbirth: a metacontent analysis of 59 studies. J Psychosom Res 1999;47:27-49.

55. Glazener CM. Sexual function after childbirth: women's experiences, persistent morbidity and lack of professional recognition. $\mathrm{Br} J$ Obste Gynaecol 1997;104:330-5. 